the coming years. The recent statement by the Minister that, by 1952 , a building programme is to be carried out which should meet all existing needs for technical education offers much encouragement and should be accompanied by the recruitment of staff possessing not only high academic or technological qualifications but also appropriate industrial experience. Men and women of suitable standard would only be obtained if the financial rewards were commensurate with those in other fields, and in every college the full permissible quota of special posts and senior assistantships should be adopted. The wide variation in the rates of payment to part-time teachers in different localities should be discontinued and superseded by a national scheme bearing a satisfactory relationship to full-time Burnham scales. Mr. Wadge also pleaded that no student who obtains a technical State scholarship should find himself precluded from taking an appropriate university course merely because he does not satisfy university entrance requirements primarily designed to assess the capacity of candidates entering directly from secondary school courses.

\section{"Colonial Month" Exhibition at the Horniman Museum}

IN connexion with the "Colonial Month" being held in London, the Horniman Museum, Forest Hill, London, S.E25, has arranged an exhibition of ethnographizal and entomological specimens from British Colonies, representative of the four continents. For America, British Guiana was chosen, and implements from the Waiwai and Wapishana tribes are shown; their personal ornaments are most colourful and usually consist of eagle and macaw feathers. From the African Continent, Nigeria and Sierra Leone are most representative from the point of view of craftsmanship ; wooden figures and masks from the Ekoi, Ibibio, Munshi and Yoruba tribes, and good examples of Benin bronzes are displayed. Oceania is represented by specimens from three different island groups, comprising the New Hebrides, Solomon Islands and Fiji. Among other exhibits, perhaps the most interesting are examples of Fijian bark-cloth, and implements used in its manufacture. In Asia, examples of the Dyak culture of Borneo complete the picture from the four continents. An exhibition of butterflies and other insects, including Papilief Hornimani, is also on view.

\section{Marinel Radar Research in Canada}

RADAR investigatipins form an important part of the programme the recently formed Radio and Electrical Divis on of National Research Council of Canad (se Not 161, 513; 1948). The Council has equifped th motor vessel Radel as a floating lalcratory to assist in the investigation of the special pro ems associated with the application of radar to mercantile marine navigation. With the opening of navigation on the Great Lakes and other Canadian inland waterways during May, the Radel, under the command of Mr. H. Ross Smyth, began her 1949 programme. The prototype model of a merchant marine radar developed in the laboratories of the Council is noteworthy for its short minimum detection-range of twenty-five yards. Some of the experiments for this year are designed to reduce this range to enable a vessel to enter narrow harbour gaps and to dock at crowded piers without needing visual aid. Another project for the work of this season is the development of coded reflector buoys, which are made non-reflecting in a periodic code sequence so as to facilitate the positive identification of the buoys used for channel and shore-line markers. Initial experiments will also be conducted on a 'microwave lighthouse', which will make it possible for ships to take accurate bearings on a shore beacon regardless of weather conditions.

\section{Hydro-Electric Potentialities of the Gold Coast}

Sir Wruliam Halcrow and Partners have agreed to undertake, on behalf of the Gold Coast Covernment, a survey of the hydro-electric potentialities of that territoyf. The survey will have particular reference fo: hydro-electric power at Ajena and/or Bui ; ingation and drainage of lands in or near the Volth catchment; and the provision of port facilities at either Ada or Accra. The terms of reference of the survey also relate to the possibility of improving transport by developing a system of navigation on the lake which would be formed by the proposed dam near Ajena and by any other means. Transport requirements which would result from the establishment of an aluminium factory will be considered. Recommendations will be made as to what proportion of the power generated by any hydro-electric schemes should be devoted to aluminium production and what proportion to other industries and towns. The effect of development on native systems of land tenure and water rights will receive special examination. The survey panel will be composed primarily of engineers provided by the firm of consultants and of Government geological, soil and land experts.

\section{Atomic Physics in the United States $\$ 7 / 6$}

Among the importantfartigles in the current issue of American Scientist N7, No. 2; April 1949) is one by J. Tiompo fut John A. Wheeler of Princeton University which gives a valuable list of original papers degling with researches in atomic physics. Recent a vances in this field have been so rapid that the production of general treatises and monographs has lagged behind the output of original papers. Tiomno and Wheeler's list, which includes references to papers announced up to December 1948, is divided into two parts, the first enumerating the major topics in atomic physics and the second the list of references themselves. The article is preceded by one by Carl D. Anderson of the California Institute of Technology reviewing the historical development of the physics of elementary particles.

\section{Merger of Management Institutes}

Av agreement defigned to bring about a merger between the Britis Institute of Management and the Institute fo Industrial Administration by two stages has rocently been signed. During the first stago, Mich comes into effect immediately, the Inst tute of Industrial Administration, which has been in existence for thirty years and has a membership of six thousand, will retain its separate identity, and its professional activities will continue unchanged; but its executive management, subject to the policy control of its own Council, will be under. taken by the staff of the British Institute of Management. The merger will be completed in the second stage, which is expected to come into effect in two or three years time. Meanwhile, the British Institute of Management will encourage managers desiring professional qualifications in general management to join the Institute of Industrial Administration. 